\title{
INFLUENCE OF WIND WAVES ON THE FLOW IN FLOWING RESERVOIRS
}

\author{
Sobir Samatovich Eshev, Alisher Normurodovich KHAZRATOV*, \\ ASHRAF RASUl O'GLi RAHIMOV AND SHAHbOZ Alisher O'GLI LATIPOV \\ "Operation of Hydraulic Structures and Pumping Stations" Department, \\ Karshi Engineering Economics Institute, Karshi, Uzbekistan \\ *Corresponding author: Khazratov@gmail.com
}

(Received: $4^{\text {th }}$ January 2019; Accepted: $18^{\text {th }}$ February 2020; Published on-line: $4^{\text {th }}$ July 2020)

\begin{abstract}
Methods are given for calculating the formation of wind waves in flowing reservoirs, taking into account oncoming and associated currents and the limitation of acceleration by the banks.

ABSTRAK: Kaedah diberikan bagi mengira pembentukan gelombang angin dalam takungan aliran, dengan mengambil kira arus datang dan aliran berkaitan dan kekurangan pecutan pada tebing.
\end{abstract}

KEYWORDS: wave action; spectral component; method of characteristics; acceleration length; wave beam

\section{INTRODUCTION}

Additional factors that determine the generation of wind waves at large watercourses (flowing reservoirs, large rivers, and large canals) in comparison to the open sea are the current and the limited acceleration by the coasts. The combined effect of both factors was studied in [1-10]. We will review the corresponding theory that underlies the methodology for calculating the formation of wind waves on watercourses.

For wind waves on a large-scale flow, the main dynamic equation is the conservation equation, which with respect to the problem under consideration can be written as:

$$
\frac{\partial N}{\partial t}+\vec{r} \bar{\partial} \vec{r} \quad O K \quad-\ldots .
$$

where:

$$
\mathrm{N}(\overrightarrow{\mathrm{r}}, \overrightarrow{\mathrm{k}}, \mathrm{t})=S(\vec{r}, \vec{k}, t) / \omega_{r}
$$

spectral density of the wave action $S(\vec{r}, \vec{k}, t)$ is the spatial amplitude spectrum of the waves, $\omega_{r}-$ is the frequency corresponding to the spectral component $\vec{k}\left(k_{x}, k_{y}\right)$ at the point $\vec{r}(x, y)$ at time $t$ in the reference frame moving with the flow velocity $\vec{U}(\vec{r}, t)$. The principle of conservation of wave action is valid for waves in a moving environment, was established by Bretherton, Garret in 1969 [9], and was developed for waves on water by Uizem.

In the one-dimensional case, equation (1) is simplified as follows: 


$$
\frac{\partial N}{\partial t}+\frac{\partial x}{\partial t} \frac{\partial N}{\partial x}+\frac{\partial k}{\partial t} \frac{\partial N}{\partial \vec{k}}
$$

Characteristics of equation (3):

$$
\begin{gathered}
\frac{\partial x}{\partial t}=\frac{\partial \omega}{\partial k}=C_{a g} \\
\frac{\partial k}{\partial t}=\frac{\partial \omega}{\partial x}=0
\end{gathered},
$$

where $C_{g a}$ is the absolute group velocity, $C_{a g}=C_{g r}=U$. In accordance with (3) and (4), the condition on the characteristics has the form:

$$
\frac{\partial N}{\partial t}+C_{a g} \frac{\partial N}{\partial x}=Q_{a c t}
$$

In the steady state, when sufficient time is reached, the wave action ceases to depend on time, but is only a function of acceleration. Moreover, equation (5) takes a very simple form:

$$
C_{a g} \frac{\partial N}{\partial x}=Q_{a c t} .
$$

Therefore, using the method of characteristics and dividing the variables in equation (6), we can write the solution of equation (3) in the following implicit form:

$$
\int_{N_{0}}^{N} \frac{d N}{Q_{a c t}}=\int_{\mathrm{x}_{0}}^{\mathrm{x}} \frac{\mathrm{dx}}{\mathrm{C}_{\mathrm{ag}}},
$$

where

$$
N=\left.N_{0}\right|_{x=x_{0}}
$$

is a boundary condition. Under the initial condition $x_{0}$, the wave factor $N_{0}$ corresponds to $x_{0} \rightarrow N_{0}$, in a certain section $x$, the wave factor $N$ corresponds $x \rightarrow N$.

Since the group velocity at constant depth and flow velocity does not depend on the coordinate, the right-hand side of equation (7) is reduced to:

$$
\int_{\mathrm{x}_{0}}^{\mathrm{x}} \frac{\mathrm{dx}}{\mathrm{C}_{\mathrm{ag}}}=t-t_{0}=\frac{x-x_{0}}{C_{a g}},
$$

where $t-t_{0}$ is the propagation time of waves with a group velocity from the boundary alignment. From (7) and (9) it follows that the following coordinate transformation (for $\left.x_{0}=0\right)$ is:

$$
\frac{x}{C_{a g}}=\frac{X}{C_{g 0}} \text { or } \frac{\mathrm{X}}{\mathrm{x}}=\frac{C_{g 0}}{C_{a g}}
$$

where $C_{g 0}$, the group velocity on still water, gives a wave action value $N(x)$ equal to $N_{0}(x)$ at the acceleration distance $x$ along the flow, which is the amount of wave action 
on the take-off run $X$ on still water. Thus, relation (10) determines the effective acceleration length for wind waves in the flow.

The definition of the effective acceleration length for waves in a flow was considered in more detail in [6], where, in particular, it was shown that if the angle between the wind and current vectors is equal to $\alpha$, then the effective acceleration length is determined by the relation:

$$
\frac{\mathrm{X}}{\mathrm{x}}=\frac{C_{g 0}}{C_{g r}+U \cos \alpha},
$$

where $C_{g r}$ is the group velocity of the waves in the coordinate system associated with the flow.

The concept of the effective acceleration length for waves in a flow gives the correct qualitative tendency for the influence of the flow on the development of waves. Indeed, in deep water $C_{g a}=C_{g 0}+U$ and in the associated stream $(U>0)$ it follows from (10) that $X / x<1$, i.e. effective acceleration length is less than actual. On the contrary, in the opposite flow $(U<0)$ it follows from $(10)$ that $X / x>1$, i.e. effective acceleration length is greater than the actual geometric length. Such a flow effect corresponds to the data obtained in aero hydrodynamic channels [11-13], where the wind waves in the passing current are less and are more in the opposite flow than in the absence of the flow, in other equal conditions.

The effective acceleration length can be determined from equation (11), in which it is necessary to set the value of the relative group velocity. For this, the experimental dependence for the frequency of the maximum of the wave spectrum in the coordinate system of the flow can be used [13]:

$$
\frac{u_{*} f_{p r}}{g}=0,939\left(\frac{g X}{u_{*}^{2}}\right)^{-0,354},
$$

where $u_{*}$ is the wind friction velocity in a fixed coordinate system. If we go in relation (12) to the wind speed and the average frequency in the spectrum using the following relations [14]:

$$
W=25 u_{*} \quad \bar{f}=1,17 f_{p},
$$

then the expression (12) takes the form:

$$
\frac{\bar{\omega}_{r} W}{g}=14,28\left(\frac{g X}{u_{*}^{2}}\right)^{-0,354},
$$

where $\omega_{r}$ is the average relative circular frequency. Then for the average group speed we get:

$$
\bar{C}_{g r}=\frac{0,44 W}{4 \pi}\left(\frac{g X}{u_{*}^{2}}\right)^{-0,354} .
$$

For the effective acceleration length, from the relation (11) the following implicit equation is obtained: 


$$
\frac{X}{x}=\frac{1}{\left(\frac{X}{x}\right)^{0,354}+\frac{4 \pi}{0,44} \frac{U \cos \alpha}{W}\left(\frac{g x}{W^{2}}\right)^{-0,354}} .
$$

The numerical solution of equation (16) is shown in Fig. 1. In Fig. 1a, the solution relates to the associated flow, when $U \cos \alpha / W>0$ and $X / x<1$. Figure $1 \mathrm{~b}$ shows the solution for the oncoming flow: $U \cos \alpha / W<0$ and $X / x>1$. The curves in Fig. 1 clearly demonstrate how important the flow factor can be, which can increase or decrease the acceleration length, especially at limited acceleration lengths.
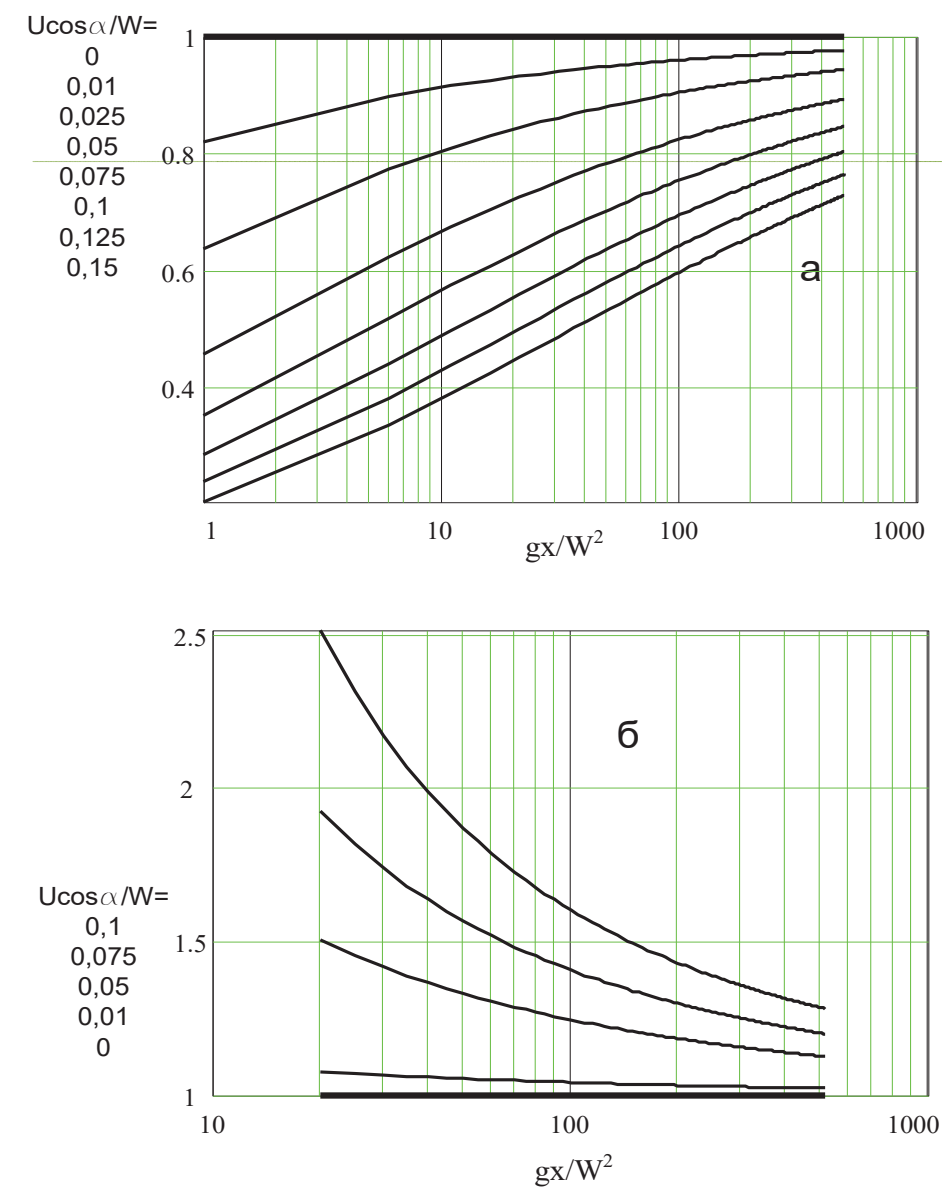

Fig. 1: The dimensionless acceleration length for wind waves in the flow:

a) on the passing flow, b) on the oncoming flow.

The introduction of an effective acceleration length allows the following formulas of GOIN-SoyuzMorNIIproekt [5] to be used to calculate the average height and period of waves in flows [5]:

$$
\begin{aligned}
& \frac{g \bar{H}}{W^{2}}=0,16\left\{1-\left[\frac{1}{1+6,0 \times 10^{-3}\left(g X / W^{2}\right)^{0,5}}\right]^{2}\right\} \operatorname{th}\left\{0,625 \frac{\left(g d / W^{2}\right)^{0,8}}{1-\left[\frac{1}{1+6,0 \times 10^{-3}\left(g X / W^{2}\right)^{0,5}}\right]}\right\}, \\
& \frac{g \bar{T}_{r}}{W}=3,1 \times 2 \pi\left(\frac{g \bar{H}}{W^{2}}\right)^{0,625}
\end{aligned}
$$


where $T_{r}$ is the period of waves in a moving coordinate system (in the flow system), $d$ - is the water depth at acceleration. As shown in [5], dependences (17) are consistent for the absence of flow with a large amount of data from field measurements of waves.

When predicting wind waves in limited water areas (large rivers, canals, reservoirs, or the coastal zone of the sea), it is necessary to take into account the limitation of acceleration by the coastline. This factor in conditions of narrowness or complex configuration of the coastline can be no less important than the current.

The principle of taking into account the influence of the coastline on acceleration limitation is known. For the coastal zone of the sea, the corresponding techniques are given in [15]. For estuaries, straits, and canals that can be approximated in plan by a rectangle, a technique for accounting for the limited channel width is given in [16].

The effective acceleration length is also used, which we will call effective to limit acceleration. The latter value is determined by the integration of the acceleration lengths measured from the design point to the intersection with the coastline, along the angle between the local and general directions of the wind speed:

$$
\frac{F}{x}=\int_{-\theta^{\prime}}^{\theta^{\prime}} p(\theta) x(\theta) d \theta / \int_{-\theta^{\prime}}^{\theta^{\prime}} x d \theta
$$

where $\theta^{\prime}$ is the raster of angles of the effective wave-forming action of the wind, $p(\theta)$ - is the weight function.

The effective wave formation raster is set at 90 degrees on both sides of the general direction for the complex outline of the coastline and from 30 to 90 degrees in the case of watercourses. The type of weight function depends on the distribution of wind speed in the directions and on local conditions. So with $\theta^{\prime}=30^{\circ}$ and $p(\theta)=1$, we get a solution often used for channels:

$$
\frac{F}{x}=\frac{6}{\pi}\left[\ln \operatorname{tg}\left(\frac{1}{2} \operatorname{arctg} \frac{b}{2 x}+\frac{\pi}{4}\right)-1,317 \frac{b}{2 x}-\frac{b}{2 x} \ln \operatorname{tg}\left(\frac{1}{2} \operatorname{arctg} \frac{b}{2 x}\right)\right],
$$

where $b$ is the channel width. The form of the function (19) is shown in Fig. 2.

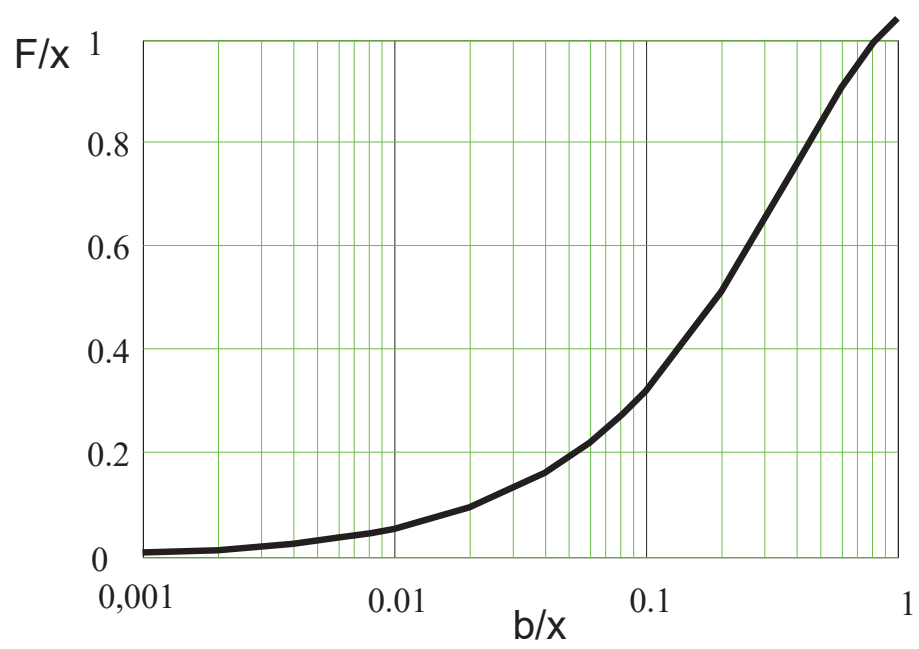

Fig. 2: The influence of the relative width of the channel on the acceleration of waves. 


\section{METHODOLOGY}

The calculation method, taking into account the influence of both the current and the complex configuration of the coastline, is as follows and is used further to calculate the size of wind waves in the region of the investigated transition. The principles of the technique are described in detail in $[7,8]$.

The algorithm is a generalization of the method of calculating wind waves with a complex coastline configuration. From the calculated point with an interval of 22.5 degrees on both sides of the main beam with number $n=1$, additional rays with numbers $n= \pm 2, \pm 3, \pm 4$ are drawn. Then, for each beam, the effective acceleration length along the stream is determined:

$$
X(\alpha)=\Delta \sum_{i=1}^{n}\left(\frac{X}{x}\right)_{i}
$$

where $\Delta$ is the length of the calculated section, $(\mathrm{X} / \mathrm{x}) \mathrm{i}$ is determined by formula (16), in which the corresponding projection of the flow velocity takes part. The beam continues until it crosses the shoreline. In the case of relatively small accelerations, we can neglect the curvature of the wave beam and use relation (20) for the beam as a whole.

Further, for each wave beam, the average wave height is calculated according to the first formula (17), the average wave height for the studied water area is determined by weighted averaging in accordance with the recommendations [13]:

$$
\bar{H}=0,1\left\{25 \bar{H}_{1}^{2}+21\left(\bar{H}_{2}^{2}+\bar{H}_{-2}^{2}\right)+13\left(\bar{H}_{3}^{2}+\bar{H}_{-3}^{2}\right)+3,5\left(\bar{H}_{4}^{2}+\bar{H}_{-4}^{2}\right)\right\}^{\frac{1}{2}} .
$$

Then, according to the second formula (17), the average wave period is determined.

To move from the average height and period of the waves to the height and period of the specified provision, the system uses the distribution function of the heights of the wind waves in the form of the Rayleigh distribution, which is assumed to be valid for effective acceleration. In particular, to determine the height and period of significant waves, the following ratio can be applied:

$$
\bar{H}=0,625 H_{s} \quad \bar{T}=0,9 T_{s} .
$$

As measurements show, for the oncoming flow, there is a feature related to the initial acceleration section. In this area, the generated wind waves propagate along the downstream, and in the wind, i.e. groups of waves propagate upstream. It is natural to assume that for a given wave the length of the initial section is determined by the relation:

$$
C_{g r}=U|\cos \alpha|,
$$

That, using expression (15) for group velocity, can be written as:

$$
\left(\frac{X}{x}\right)^{0,354}-\frac{4 \pi}{0,44} \frac{U}{W}\left(\frac{g x}{W^{2}}\right)^{-0,354}|\cos \alpha|=0 .
$$

If we solve equations (24) and (16) together for a ray in the opposite flow, then we can take into account the effect of the initial section. 


\section{RESULTS AND CONCLUSION}

The developed methodology is confirmed by field measurements made at the Karakum channel (on the 110-120 km section of the canal) by the authors of the report, as well as by the SANIIRI measurement data on several Central Asian channels [6]. For an idea of the ranges of the comparison, the author's measurement data along with the calculation data are presented in Table 1. The table shows that a comparison of the results of calculating the heights of the wind waves with the measurement data give a good ratio.

Table 1: Comparison of wind wave height calculation results with measurement data

\begin{tabular}{ccccccc}
\hline $\begin{array}{c}\text { Acceleration } \\
\text { length }[\mathbf{m}]\end{array}$ & $\begin{array}{c}\text { Channel } \\
\text { width }[\mathbf{m}]\end{array}$ & $\begin{array}{c}\text { Water depth } \\
{[\mathbf{m}]}\end{array}$ & $\begin{array}{c}\text { Wind speed } \\
{[\mathbf{m} / \mathbf{s}]}\end{array}$ & $\begin{array}{c}\text { Flow } \\
\text { velocity }[\mathbf{m}]\end{array}$ & \multicolumn{2}{c}{ Mass [kg] } \\
\hline 256 & 134 & 4.6 & 5.3 & -0.42 & 4.5 & 4.3 \\
258 & 134 & 4.6 & 6.9 & -0.42 & 5.8 & 6.7 \\
258 & 134 & 4.6 & 4.1 & -0.42 & 3.3 & 3.0 \\
795 & 167 & 3.8 & 5.7 & 0.42 & 6.0 & 6.1 \\
795 & 167 & 3.8 & 5.8 & 0.42 & 6.3 & 6.2 \\
137 & 55 & 3.2 & 9.4 & -0.55 & 8.0 & 5.8 \\
198 & 55 & 3.2 & 6.1 & -0.55 & 5.6 & 3.7 \\
180 & 50 & 2.1 & 15.8 & -0.53 & 14.0 & 14.0 \\
125 & 50 & 2.1 & 17.2 & -0.53 & 13.0 & 11.0 \\
180 & 50 & 2.1 & 6.0 & -0.53 & 1.6 & 1.5 \\
\hline
\end{tabular}

It can be concluded that when calculating the formation of wind waves on a stream in flowing reservoirs, large and small rivers, and large channels, the proposed calculation method can be used. The proposed methods have scientific justification and allow you to get the results needed to estimate the turbidity fields during dredging, determine the safe depth of the pipeline, predict possible erosion along the route, and calculate the wave deformation of the bottom and coastal slopes of the watercourse. The presented calculation methods and models can be applied to various areas of large watercourses or the coastal zone of the sea for the scientific justification of works on the construction of crossings by pipelines.

\section{REFERENCES}

[1] Atazhanov A, Kantargi IG, Sapova NO. (1989) Development of a method for predicting wind waves on streams. Proceedings of the VNII VODGEO, M., VODGEO, 40-45.

[2] Zairov HI, Listrova PP, Masumov RR. (1986) Prediction of wind wave elements in large channels. Hydraulic Engineering, 12:44-46.

[3] Kantargi IG (1987) A method for predicting wind waves on streams. Tr. VNII VODGEO, M, VODGEO, 60-68.

[4] Kantargi IG, Dreisis YuI., Chebotkevich VO. (1987) The forecast of wind waves in large canals and flowing reservoirs. Hydraulic Engineering and Land Reclamation, 2: 24-27.

[5] Krylov YuM., Strekalov SS, Tsyplukhin VF. (1976) Wind waves and their impact on structures. Leningrad, Gidrometeoizdat.

[6] Mass EI, Kantargi IG. (1988) Method for calculating wind waves in large channels. Water Resources, 1:60-67. 
[7] Mass EI, Kantargi IG. (1986) Recommendations for the calculation of wind waves and sediment transport in large channels. Central Scientific Research Institute of Scientific Research, 1986, pp 1-63.

[8] Rzhanitsyn NA, Altunin VS, Voynich-Syanozhentsky TG, Mass EI, Debolsky VK, Kantargi IG and others. Recommendations for the hydraulic calculation of large channels. GKNT USSR, Soyuzgiprovodkhoz, (1986), pp 1-153.

[9] Bretherton FP, Garret CJR. (1969) Wave trains in inhomogeneous moving media. Proc. Roy. Soc. A, 302: pp 1-529.

[10] Kato H, Tsuruya H, Doi T, Mijarari Y. (1976) Experimental study of wind waves generated on water currents. 2nd report, Rep. Port Harbor Res. Inst., 15(4):3-46.

[11] Kato H, Tsuruya H, Terakawa H. (1981) Experimental study of wind waves generated on water currents. 3rd report. Wave forecasting methods and its experimental confirmation. Rep. Port Harbor Res. Inst., 20(3):94-129.

[12] Kato H, Tsuruya H. (1978) Experimental study of wind waves generated on currents. Proc. 16th Coastal Eng. Conf. ASCE, 1:742-755.

[13] Mitsuyasu H, Rikiishi. (1975) On the growth of duration-limited wave spectra. Rep. Res. Inst. Appl. Mech., Kuishi Univer., v. 23, 31-60.

[14] US Army (1984) Shore protection manual v. 2, 4th ed., Coast. Eng. Res. Center, Washington, D.C.

[15] Wood AMM. (1969) Coastal Hydraulics. Pitman Press, Both.

[16] Willis DH. (1978) Sediment Load under Waves and Current. Proc. 16th Int. Conf. on Coastal Eng. August 27-September 3, 1978; Hamburg, Germany. 